\title{
Update: non-invasive ventilation in chronic obstructive pulmonary disease
}

\author{
Neeraj Mukesh Shah ${ }^{1}$, Rebecca Francesca D'Cruz ${ }^{1,3}$, Patrick B. Murphy ${ }^{1,2,4}$ \\ ${ }^{1}$ Lane Fox Respiratory Unit, ${ }^{2}$ Lane Fox Clinical Respiratory Physiology Research Centre, Guy's and St Thomas' NHS Foundation Trust, London, \\ UK; ${ }^{3}$ National Institute for Health Research (NIHR) Biomedical Research Centre at Guy's and St Thomas' NHS Foundation Trust and King's \\ College London, London, UK; ${ }^{4}$ Division of Asthma, Allergy and Lung Biology, King's College London, London, UK \\ Correspondence to: Patrick B. Murphy. Lane Fox Respiratory Unit, St Thomas' Hospital, Westminster Bridge Road, London SE1 7EH, UK. \\ Email: patrick.murphy@gstt.nhs.uk.
}

\begin{abstract}
Chronic obstructive pulmonary disease (COPD) remains a common cause of morbidity and mortality worldwide. Patients with COPD and respiratory failure, whether acute or chronic have a poorer prognosis than patients without respiratory failure. Non-invasive ventilation (NIV) has been shown to be a useful tool in both the acute hospital and chronic home care setting. NIV has been well established as the gold standard therapy for acute decompensated respiratory failure complicating an acute exacerbation of COPD with reduced mortality and intubation rates compared to standard therapy. However, NIV has been increasingly used in other clinical situations such as for weaning from invasive ventilation and to palliate symptoms in patients not suitable for invasive ventilation. The equivocal evidence for the use of NIV in chronic hypercapnic respiratory failure complicating COPD has recently been challenged with data now supporting a role for therapy in selected subgroups of patients. Finally the review will discuss the emerging role of high flow humidified therapy to support or replace NIV in certain clinical situation.
\end{abstract}

Keywords: Non-invasive ventilation (NIV); chronic obstructive pulmonary disease (COPD); acute respiratory failure; chronic respiratory failure

Submitted Sep 21, 2017. Accepted for publication Sep 26, 2017.

doi: $10.21037 /$ jtd.2017.10.44

View this article at: http://dx.doi.org/10.21037/jtd.2017.10.44

\section{Introduction}

The use of bilevel non-invasive ventilation (NIV) in patients suffering from an acute exacerbation of chronic obstructive pulmonary disease (COPD) complicated by hypercapnic respiratory failure is widespread, supported by a strong evidence base and benefits from clinician consensus on its value. Its use in other conditions in COPD patients is more controversial. This review will initially discuss recent developments around patient selection and weaning from NIV during an acute episode. This will be followed by an update on the use of home NIV in patients with persistent hypercapnia, its use as an adjunct to an exercise training programme and in the palliative care setting. Finally, the use of humidified oxygen via nasal cannulae will be discussed as a more recent potential alternative to NIV in these patients.

\section{NIV in acute hypercapnic respiratory failure}

The utility of NIV in acute hypercapnic respiratory failure in COPD is well-established. Since the mid-1990's, studies have demonstrated superior outcomes in patients with hypercapnic respiratory failure during COPD exacerbation when treated with NIV compared to management without NIV $(1,2)$. It is now a standard component of the management of these patients and is included in the most recent international guidelines $(3,4)$. Established criteria for patient selection include persistent acidosis $(\mathrm{pH}<7.35)$, hypercapnia $\left(\mathrm{pCO}_{2}>6.5 \mathrm{kPa}\right)$ or tachypnoea (respiratory rate $>22$ breaths per minute) despite optimal bronchodilator and controlled oxygen therapy (3). Despite these standardised criteria and increasing experience with NIV therapy outside of the critical care setting, the rate of failure of NIV therapy is still reported to be as high as $20-$ 
Box 1 Prognostic factors associated with NIV failure

Patient factors
Radiological consolidation
High secretion load
Poor nutritional status
Intervention factors
Patient ventilator asynchrony
High leak levels
Outcome factors
Failure to have physiological improvement in gas exchange in
$1^{\text {st }}$ hour of therapy

NIV, non-invasive ventilation.

$30 \%(5-7)$. Interest now focuses on refining these criteria to ensure NIV is given to the most appropriate patients and thus improve outcomes.

When compared with invasive mechanical ventilation in randomised clinical trials, observational cohorts or metaanalyses, NIV has been shown to have better outcomes (reduced inpatient mortality and length of stay) $(1,8,9)$. This can be explained by a higher complication rate in the group treated with invasive mechanical ventilation. The need for NIV in acute exacerbations of COPD itself continues to be a poor prognostic factor. In a cohort of 757 patients admitted to hospital with an acute exacerbation of COPD, treatment with NIV was an independent marker of 1 -year mortality (10). This is likely to represent the severity of the underlying COPD and comorbid status at the time of an exacerbation, and which is beyond clinician control. It does, however, emphasise a need to optimise the disease management of these patients.

NIV failure is associated with higher in-hospital mortality, length of hospital and critical care stay than NIV success (6). It is important to have markers to predict NIV failure prior to initiation of therapy, to either provide more intensive treatment in the form of invasive mechanical ventilation or allow a more conservative approach, if palliation is the most appropriate strategy. A higher APACHE II score (>20.5) at presentation can predict failure of NIV in these patients $(6,11)$; however, this marker is rarely used outside of the critical care setting. Other markers that may predict NIV failure include younger age, lower arterial bicarbonate levels, lower $\mathrm{PaCO}_{2}$ and high arterial lactate (6). Others have identified baseline anaemia (12), World Health Organization-Performance
Status (12) and a nutritional risk screening 2002 score of greater than 3 (13). Patients with evidence of diaphragmatic dysfunction at the time of admission are also more likely to suffer from NIV treatment failure (14). Persistent tachycardia and acidosis 1 hour after initiation of NIV also had an association with treatment failure (15). With further work, the above factors have the potential to become more extensive inclusion and exclusion criteria for use in making decisions about offering NIV in acute exacerbations of COPD. Using more stringent criteria to select candidates for NIV may also improve outcomes. A prognostic tool for clinicians is being addressed by the NIV outcome (NIVO) study in the UK, building on the DECAF score derived for all patients with exacerbations of COPD by the same group, which should report its findings next year (Trial registration: ISRCTN22921168) (16,17).

A recent qualitative study, investigating clinician factors that contribute to NIV success or failure in 'highperforming' centres in the USA, has demonstrated that ensuring adequate staffing with respiratory physiotherapists is a key factor for successful NIV delivery (18). Important prognostic factors for NIV failure are summarised in Box 1 .

Once NIV therapy has been initiated, the timing of withdrawal also needs to be considered. The 2016 BTS/ ICS guideline state that NIV can be discontinued once the acidosis and hypercapnia have resolved, in a stepwise manner to avoid relapse of the hypercapnic failure (3). There is scarce literature to support this approach compared with immediate withdrawal. A small pilot study compared outcomes between stepwise and immediate withdrawal of NIV (19). They failed to demonstrate any difference in outcome, however there was concern about the study being underpowered.

A recent RCT has compared immediate withdrawal with three further days of nocturnal NIV, once the acidosis had resolved and clinical parameters have stabilized (20). The study primary end-point was relapse of hypercapnic respiratory failure within eight days of discontinuation. Secondary end-points were dependency of NIV, length of stay, hospital mortality and survival and readmission at six months. No differences were observed between the two arms of the trial. Although this is one of few trials to compare the two strategies, it challenges the conventional approach of stepwise withdrawal and necessitates more studies to be performed to clarify this further.

\section{NIV in chronic hypercapnic respiratory failure}

The potential benefit of providing intermittent offloading 
of respiratory muscles in patients with chronic hypercapnic failure with mechanical ventilation has been long postulated (21). Early studies used the negative pressure 'Body-Type Respirator' with very limited success and this approach was eventually abandoned. The concept of ventilatory support in chronic respiratory failure was reinvigorated in the 1990's with the development of positive pressure devices suitable to deliver home NIV. Although COPD is a common indication for domiciliary $\operatorname{NIV}(22,23)$, the evidence base for its use remains equivocal (24).

Several meta-analyses and a Cochrane systematic review concluded that there was insufficient evidence to support the routine use of domiciliary NIV in patients with COPD (25-29). Although some of these trials have demonstrated an improvement in $\mathrm{PaCO}_{2}$, there was no objective improvement in lung function, hospitalizations or mortality, and a non-significant tendency to improve quality of life (QoL).

Since these meta-analyses, several studies have published varying results. A retrospective review of patients requiring acute NIV for an exacerbation of COPD reported a better event-free survival in patients receiving domiciliary NIV than in patients without (30). There was, however, no effect on mortality when considered alone. A review of a quality improvement programme in patients with at least two admissions due to COPD with hypercapnic failure demonstrated a reduction in the number of admissions due to COPD with domiciliary NIV, when combined into a treatment package with medicines rationalization, outpatient respiratory physiotherapy, patient education and long-term oxygen therapy (LTOT) where indicated (31). There was no comment on mortality in this study and the effect of NIV is difficult to separate from the other aspects delivered in this multi-modal intervention. A smaller randomised controlled trial has demonstrated improved QoL indices at three months but not six months in the domiciliary NIV cohort compared with the standard treatment cohort (32). Another small study $(\mathrm{n}=10)$ has demonstrated improved $\mathrm{PaCO}_{2}$, exercise tolerance [measured as 6-minute walking distance (6MWD)] and anxiety levels [measured in the anxiety domain of the Severe Respiratory Insufficiency Questionnaire (SRI)] (33).

Four recent randomised controlled trials investigating domiciliary NIV have been identified. The RESCUE trial, a multicentre cohort from The Netherlands, compared initiation of domiciliary NIV with standard treatment after an admission with hypercapnic respiratory failure (34). It reported no mortality benefit and no reduction in admissions or COPD exacerbations in the year after discharge. There was a non-significant trend to improved health-related QoL. A multicentre randomised controlled trial from China comparing patients receiving LTOT with domiciliary NIV + LTOT. Although there was a significant reduction in daytime $\mathrm{PaCO}_{2}$ and increase in $6 \mathrm{MWD}$ with domiciliary NIV + LTOT, there was no mortality benefit, improvement in lung function or QoL (35).

In contrast to these studies, a multicentre trial from Germany and Austria comparing domiciliary NIV titrated to reduced daytime $\mathrm{PaCO}_{2}$ with standard care in patients with chronic stable hypercapnic respiratory failure reported a significantly reduced 1-year all-cause mortality in the NIV group (36). Furthermore, a recent multicentre randomised controlled trial from the United Kingdom, which randomised patients to receive home oxygen or domiciliary $\mathrm{NIV}+$ home oxygen, at least two weeks after normalisation of respiratory acidosis secondary to acute hypercapnic respiratory failure, has reported positive results (37). The group receiving domiciliary NIV + home oxygen had a significantly longer admission-free survival compared with the group receiving home oxygen alone. These are some of the first RCTs to demonstrate a mortality benefit in patients receiving domiciliary NIV; if this can be replicated in other studies it has the potential to form a strong rationale to implement screening for persistent hypercapnia after discharge, in patients who require acute NIV for COPD.

In line with the findings of the RESCUE trial, a recent meta-analysis of the effect of home NIV in COPD has reported no mortality benefit and no reduction in exacerbation frequency, with only a trend towards reduced length of stay and improved health-related QoL (38). This analysis does not take into account the results of the Chinese or UK trials and the results are unsurprising as the RESCUE study was the largest study in the meta-analysis recruiting more than 4 times the number of patients than any other included study. Furthermore, the results of an ongoing trial in Denmark comparing domiciliary NIV with standard care after acute hypercapnia are awaited (39).

The discrepancy in results between trials may be related to population selection and it will be important to determine criteria for selecting suitable patients who will benefit from domiciliary NIV. Obesity appears to be a protective factor in this patient group. Patients receiving domiciliary NIV with a BMI $>30 \mathrm{~kg} / \mathrm{m}^{2}$ had longer survival compared with those with a BMI $20-30 \mathrm{~kg} / \mathrm{m}^{2}(40,41)$. It is recognised that obstructive sleep apnoea (OSA) is a common feature in obese patients, and so this protective 
effect could be due to the effect of NIV of improving the OSA; however even with adjustment for OSA, obesity appeared to have a protective effect (41). Furthermore, Murphy et al. excluded patients with OSA from their trial; demonstrating that domiciliary NIV has a survival benefit over and above its effect on treating OSA (37). The mechanism for this is unclear but is likely to be related to the obesity paradox observed in critical care patients $(42,43)$. Although this was previously seen only in patients requiring invasive mechanical ventilation $(44,45)$, it has now been demonstrated in patients who also require NIV (40).

Patient-ventilator asynchrony (PVA) is associated with impaired respiratory muscle unloading (46), patient intolerance to ventilator therapy $(47,48)$ and worsened dyspnoea perception (49). Despite this, PVA has been demonstrated to have no impact on overnight gas exchange during set-up of domiciliary NIV (50). The importance of correcting PVA is therefore unclear and patient comfort and control of gas exchange should remain the principal targets for establishing successful home NIV titration.

Worse health status, measured with SRI and the St George's Respiratory Questionnaire, was significantly associated with worse mortality in patients receiving domiciliary NIV, independently of nutritional status, $\mathrm{PaCO}_{2}$ and pulmonary function (51). In the elderly ( $>75$ years), domiciliary NIV failed to improve healthrelated QoL, whereas there was a significant improvement in the under 75 age group (52). Of note, these studies were not performed in patients with COPD specifically.

\section{NIV as an adjunct in exercise training}

Exercise training, in the form of pulmonary rehabilitation, is a key tenet in the management of COPD (53). A structured exercise programme improves health-related QoL and reduces the number of admissions $(54,55)$, and reduces mortality (56-59). A limitation to prolonged exercise training in patients with COPD is the development of dynamic hyperinflation due to an increase in end-expiratory volume caused by expiratory flow limitation and increased respiratory rate (60). There is increasing interest in the use of NIV as an adjunct during exercise training, due to its effect of unloading the respiratory muscles and therefore improving exercise capacity $(61,62)$.

Despite this theoretical value of NIV during exercise training, little high quality evidence supports its use. The combination of home NIV and exercise training has been demonstrated to deliver a larger improvement in blood gases than either intervention alone (63). Home NIV resulted in a greater improvement in $6 \mathrm{MWD}$ when coupled with pulmonary rehabilitation than rehabilitation alone both in controlled and uncontrolled studies (64-66). However, systematic reviews and meta-analyses are unable to recommend the addition of NIV during exercise therapy due to the lack of supporting evidence (67-69).

\section{NIV in palliative care}

Breathlessness is a cardinal symptom of COPD, which progresses with advancing disease and has a profound impact on patients' QoL. There is no widely accepted method of either predicting prognosis or defining endstage COPD (70), which may contribute to the wide variation and lower quality of end-of-life care for COPD patients compared to lung cancer patients $(71,72)$. The American Thoracic Society recommend that palliative care should be available to all patients regardless of the stage of their disease and that relieving the dyspnoea should be a key consideration (73). The palliation of dyspnoea may have benefits extending beyond symptom relief with some evidence of an impact on mortality from dyspnoea specific palliative care programmes (74). NIV is used in nearly one third of COPD patients considered to have a poor life expectancy (71). Its use in this setting has a weak evidence base but used judiciously can contribute to symptom relief without adding to the care burden.

NIV can relieve breathlessness by unloading the respiratory muscles. One prospective cohort study in a population of patients with solid organ cancers demonstrated that NIV significantly reduced breathlessness and oxygenation (75). However, there are barriers that prevent its widespread use, including perceptions amongst both patients and clinicians that NIV can prolong suffering during the dying process (76) since the mask can be uncomfortable, claustrophobic and may impede communication with friends and relatives.

The intended goals of NIV should therefore be established prior to its use in patients considered to be in the final stage of their life with clear communication between patients, carers and healthcare teams. Identification of rationale of therapy, expected response, treatment escalation and or withdrawal of therapy should be clearly documented at the initiation of therapy (76).

In summary, there should be clear dialogue between patients and their healthcare teams regarding their diagnosis, prognosis, advanced care planning and anticipated symptoms, 
irrespective of the stage of their disease. Early discussions should be had regarding palliation of symptoms, particularly breathlessness. This can be alleviated using pharmacological or non-pharmacological methods, which may include NIV.

\section{High flow humidified oxygen via nasal cannula (HFNC)}

HFNC is an emerging oxygen delivery system. HFNC consists of an air-oxygen blender which generates gas flow of up to $60 \mathrm{~L} / \mathrm{min}$ which is humidified, heated and delivered to the patient via wide-bore nasal cannulae. There is a growing body of evidence to support the use of HFNC in the critical care setting in patients with acute hypoxaemic respiratory failure without hypercapnia. Its benefits when compared to conventional oxygen via face mask and NIV are considered to be multifactorial and will be discussed here. More work is needed to assess the role of HFNC in acutely hypercapnic patients.

Several studies have demonstrated that the HFNC interface is better tolerated than conventional oxygen and NIV (77-79). The humidified system causes fewer side effects of nasal and throat dryness and or pain. Patients therefore tolerate the device for longer, leading to fewer episodes of interface dislodgement with associated desaturations (80).

HFNC has demonstrable physiological benefits with the high flow rate reducing anatomical dead space thereby improving alveolar ventilation. It also creates positive nasopharyngeal pressure which can reach $7 \mathrm{cmH}_{2} \mathrm{O}$ at $50 \mathrm{~L} / \mathrm{min}$ (81) which supports alveolar recruitment and may create an oxygen reservoir (82). The delivery of a constant fraction of inspired oxygen $\left(\mathrm{FiO}_{2}\right)(81)$ and ability to achieve high flow rates above that possible with conventional oxygen (maximum $15 \mathrm{~L} / \mathrm{min}$ ) allows the delivery flow rate to better match that of the patient in acute respiratory failure, whose inspiratory flow can reach up to $100 \mathrm{~L} / \mathrm{min}$ (83).

HFNC has been evaluated in the critical care setting as an alternative to conventional oxygen and NIV in acute hypoxaemic respiratory failure and post-extubation. Large well conducted randomised clinical trials have demonstrated efficacy of HFNC in critical care in patients with both low (84) and high (including patients with COPD) risk of extubation failure (85). HFNC reduced the risk of reintubation within 72 hours compared to conventional oxygen and was non-inferior to NIV in preventing reintubation and post-extubation hypercapnic respiratory failure. Stéphan et al. (86) also found HFNC to be non-inferior to NIV in preventing or resolving acute respiratory failure in 830 post-cardiothoracic surgery patients. Furthermore HFNC produce better oxygenation at a comparable $\mathrm{FiO}_{2}$ with lower $\mathrm{PaCO}_{2}$ and respiratory rate than conventional oxygen therapy delivered by Venturi mask (80). In patients with acute hypoxaemic non-hypercapnic respiratory failure evidence is emerging that HFNC may confer a survival advantage compared to conventional oxygen therapy or NIV(87).

Evidence to support the use of HFNC in acutely hypercapnic patients is limited to small studies and case reports. HFNC has been used successfully in patients with acute hypercapnic respiratory failure who decline NIV (88). The use of HFNC has been associated with minor respiratory physiological improvements in patients with COPD during acute exacerbations (mild reduction in transcutaneous $\mathrm{CO}_{2}$ ) (89) and in patients with stable severe COPD (reduction in capillary $\mathrm{CO}_{2}$ tension, respiratory rate and dyspnoea and increased tidal volumes) (90).

In summary, HFNC is an emerging method of humidified and heated oxygen delivery which allows an accurate and constant $\mathrm{FiO}_{2}$ to be delivered at high flow rates which can additionally create a small positive mean airway pressure. It is well tolerated by patients and there is evidence to support its use in the critical care setting in non-hypercapnic acute hypoxaemic respiratory failure and post-extubation. HFNC appears to reduce $\mathrm{PaCO}_{2}$ in stable COPD however more work is needed to investigate its use in acute hypercapnic respiratory failure. NIV is the accepted standard of care; however, HFNC may be an option to allow breaks from NIV for medication, hydration, nutrition and comfort to enhance the efficacy of NIV or for those unable to tolerate NIV.

\section{Summary}

NIV is an effective and evidence-based therapeutic tool in patients with acute exacerbations of COPD complicated by hypercapnic respiratory failure. Selection of appropriate patients to reduce the rate of NIV failure remains a challenge but recent studies have provided some insight into possible predictors of NIV failure. With further evaluation, these could contribute to the refinement of eligibility criteria for NIV. The most effective strategy to withdraw NIV once acidosis and hypercapnia have normalized remains elusive with new data suggesting that immediate withdrawal of NIV is safe and does not contribute to relapse any more than a step-wise withdrawal. This challenges the conventional approach taken and needs more assessment before adoption into wider clinical practice. The evidence 
supporting the use of domiciliary NIV in patients who have previously suffered from an acute hypercapnic episode and remain persistently hypercapnic continues to grow. Several recent RCTs have demonstrated favourable outcomes with domiciliary NIV when applied to specific phenotypes of patient with a titration policy directed at reduction of $\mathrm{PaCO}_{2}$ and control of sleep disordered breathing. This has the potential to significantly change clinical practice and has implications for long-term management of endstage COPD patients and the costs attracted to their management. Little recent evidence suggests that NIV used as an adjunct in exercise training in COPD improves clinical outcomes; while its use in palliative care favours the subjective perception of dyspnoea more than objective markers of respiratory function. Use of HFNC continues to grow and may have a role in hypercapnic respiratory failure patients who are unable to receive NIV or invasive mechanical ventilation. The use of NIV in hypercapnic COPD patients is likely to widen over the coming years; it is crucial that we refine the criteria for offering NIV both acutely and chronically, and ensure the ventilator strategies are optimal for this important group of patients.

\section{Acknowledgements}

Dr. RF D'Cruz is supported by the National Institute for Health Research (NIHR) Biomedical Research Centre at Guy's and St Thomas' NHS Foundation Trust and King's College London.

\section{Footnote}

Conflicts of Interest: The authors have no conflicts of interest to declare.

\section{References}

1. Brochard L, Mancebo J, Wysocki M, et al. Noninvasive ventilation for acute exacerbations of chronic obstructive pulmonary disease. N Engl J Med 1995;333:817-22.

2. Bott J, Carroll MP, Conway JH, et al. Randomised controlled trial of nasal ventilation in acute ventilatory failure due to chronic obstructive airways disease. Lancet 1993;341:1555-7.

3. Davidson AC, Banham S, Elliott M, et al. BTS/ICS guideline for the ventilatory management of acute hypercapnic respiratory failure in adults. Thorax 2016;71 Suppl 2:ii1-35.

4. Wedzicha JAEC-C, Miravitlles M, Hurst JR, et al.
Management of COPD exacerbations: a European Respiratory Society/American Thoracic Society guideline. Eur Respir J 2017;49. pii: 1600791.

5. Confalonieri M, Garuti G, Cattaruzza MS, et al. A chart of failure risk for noninvasive ventilation in patients with COPD exacerbation. Eur Respir J 2005;25:348-55.

6. Corrêa TD, Sanches PR, de Morais LC, et al. Performance of noninvasive ventilation in acute respiratory failure in critically ill patients: a prospective, observational, cohort study. BMC Pulm Med 2015;15:144.

7. Ozyilmaz E, Ugurlu AO, Nava S. Timing of noninvasive ventilation failure: causes, risk factors, and potential remedies. BMC Pulm Med 2014;14:19.

8. Lindenauer PK, Stefan MS, Shieh MS, et al. Outcomes associated with invasive and noninvasive ventilation among patients hospitalized with exacerbations of chronic obstructive pulmonary disease. JAMA Intern Med 2014;174:1982-93.

9. Osadnik CR, Tee VS, Carson-Chahhoud KV, et al. Non-invasive ventilation for the management of acute hypercapnic respiratory failure due to exacerbation of chronic obstructive pulmonary disease. Cochrane Database Syst Rev 2017;7:CD004104.

10. García-Sanz MT, Canive-Gomez JC, Senin-Rial L, et al. One-year and long-term mortality in patients hospitalized for chronic obstructive pulmonary disease. J Thorac Dis 2017;9:636-45.

11. Conti V, Paone G, Mollica C, et al. Predictors of outcome for patients with severe respiratory failure requiring non invasive mechanical ventilation. Eur Rev Med Pharmacol Sci 2015;19:3855-60.

12. Haja Mydin H, Murphy S, Clague H, et al. Anemia and performance status as prognostic markers in acute hypercapnic respiratory failure due to chronic obstructive pulmonary disease. Int J Chron Obstruct Pulmon Dis 2013;8:151-7.

13. Cui J, Wan Q, Wu X, et al. Nutritional Risk Screening 2002 as a Predictor of Outcome During General WardBased Noninvasive Ventilation in Chronic Obstructive Pulmonary Disease with Respiratory Failure. Med Sci Monit 2015;21:2786-93.

14. Antenora F, Fantini R, Iattoni A, et al. Prevalence and outcomes of diaphragmatic dysfunction assessed by ultrasound technology during acute exacerbation of COPD: A pilot study. Respirology 2017;22:338-44.

15. Ko BS, Ahn S, Lim KS, et al. Early failure of noninvasive ventilation in chronic obstructive pulmonary disease with acute hypercapnic respiratory failure. Intern Emerg Med 
2015;10:855-60.

16. Steer J, Gibson J, Bourke SC. The DECAF Score: predicting hospital mortality in exacerbations of chronic obstructive pulmonary disease. Thorax 2012;67:970-6.

17. Echevarria C, Steer J, Heslop-Marshall K, et al. Validation of the DECAF score to predict hospital mortality in acute exacerbations of COPD. Thorax 2016;71:133-40.

18. Fisher KA, Mazor KM, Goff S, et al. Successful Use of Noninvasive Ventilation in Chronic Obstructive Pulmonary Disease: How Do High-Performing Hospitals Do It? Ann Am Thorac Soc 2017. [Epub ahead of print].

19. Lun CT, Chan VL, Leung WS, et al. A pilot randomized study comparing two methods of non-invasive ventilation withdrawal after acute respiratory failure in chronic obstructive pulmonary disease. Respirology 2013;18:814-9.

20. Sellares J, Ferrer M, Anton A, et al. Discontinuing noninvasive ventilation in severe chronic obstructive pulmonary disease exacerbations: a randomised controlled trial. Eur Respir J 2017;50. pii: 1601448.

21. McClement JH, Christianson LC, Hubaytar RT, et al. The Body-Type Respirator in the Treatment of Chronic Obstructive Pulmonary Disease. Ann N Y Acad Sci 1965;121:746-50.

22. Crimi C, Noto A, Princi P, et al. Domiciliary Noninvasive Ventilation in COPD: An International Survey of Indications and Practices COPD. 2016;13:483-90.

23. Crimi C, Noto A, Princi P, et al. A European survey of noninvasive ventilation practices. Eur Respir J 2010;36:362-9.

24. Shah NM, Patrick B. Hypercapnic respiratory failure in non-COPD. In: Leo Heunks L, Demoule A, Windisch W. editors. Pulmonary Emergencies. ERS Monograph. UK: European Respiratory Society Monograph, 2016;74:86-100.

25. Struik FM, Lacasse Y, Goldstein R, et al. Nocturnal noninvasive positive pressure ventilation for stable chronic obstructive pulmonary disease. Cochrane Database Syst Rev 2013;(6):CD002878.

26. Shi JX, Xu J, Sun WK, et al. Effect of noninvasive, positive pressure ventilation on patients with severe, stable chronic obstructive pulmonary disease: a meta-analysis. Chin Med J (Engl) 2013;126:140-6.

27. McCurdy BR. Noninvasive positive pressure ventilation for acute respiratory failure patients with chronic obstructive pulmonary disease (COPD): an evidence-based analysis. Ont Health Technol Assess Ser 2012;12:1-102.

28. Wijkstra PJ, Lacasse Y, Guyatt GH, et al. A meta-analysis of nocturnal noninvasive positive pressure ventilation in patients with stable COPD. Chest 2003;124:337-43.

29. Struik FM, Lacasse Y, Goldstein RS, et al. Nocturnal noninvasive positive pressure ventilation in stable COPD: a systematic review and individual patient data metaanalysis. Respir Med 2014;108:329-37.

30. Galli JA, Krahnke JS, James Mamary A, et al. Home non-invasive ventilation use following acute hypercapnic respiratory failure in COPD. Respir Med 2014;108:722-8.

31. Coughlin S, Liang WE, Parthasarathy S. Retrospective Assessment of Home Ventilation to Reduce

Rehospitalization in Chronic Obstructive Pulmonary Disease. J Clin Sleep Med 2015;11:663-70.

32. Bhatt SP, Peterson MW, Wilson JS, et al. Noninvasive positive pressure ventilation in subjects with stable COPD: a randomized trial. Int J Chron Obstruct Pulmon Dis 2013;8:581-9.

33. Hajian B, De Backer J, Sneyers C, et al. Pathophysiological mechanism of long-term noninvasive ventilation in stable hypercapnic patients with COPD using functional respiratory imaging. Int J Chron Obstruct Pulmon Dis 2017;12:2197-205.

34. Struik FM, Sprooten RT, Kerstjens HA, et al. Nocturnal non-invasive ventilation in COPD patients with prolonged hypercapnia after ventilatory support for acute respiratory failure: a randomised, controlled, parallel-group study. Thorax 2014;69:826-34.

35. Zhou L, Li X, Guan L, et al. Home noninvasive positive pressure ventilation with built-in software in stable hypercapnic COPD: a short-term prospective, multicenter, randomized, controlled trial. Int J Chron Obstruct Pulmon Dis 2017;12:1279-86.

36. Köhnlein T, Windisch W, Kohler D, et al. Noninvasive positive pressure ventilation for the treatment of severe stable chronic obstructive pulmonary disease: a prospective, multicentre, randomised, controlled clinical trial. Lancet Respir Med 2014;2:698-705.

37. Murphy PB, Rehal S, Arbane G, et al. Effect of Home Noninvasive Ventilation With Oxygen Therapy vs Oxygen Therapy Alone on Hospital Readmission or Death After an Acute COPD Exacerbation: A Randomized Clinical Trial. JAMA 2017;317:2177-86.

38. Dretzke J, Moore D, Dave C, et al. The effect of domiciliary noninvasive ventilation on clinical outcomes in stable and recently hospitalized patients with COPD: a systematic review and meta-analysis. Int J Chron Obstruct Pulmon Dis 2016;11:2269-86.

39. Ankjærgaard KL, Tonnesen P, Laursen LC, et al. Home Non Invasive Ventilation (NIV) treatment for COPD patients with a history of NIV-treated exacerbation; a randomized, controlled, multi-center study. BMC Pulm 
Med 2016;16:32.

40. Altinoz H, Adıgüzel N, Saltürk C, et al. Obesity might be a good prognosis factor for COPD patients using domiciliary noninvasive mechanical ventilation. International Journal of Chronic Obstructive Pulmonary Disease 2016; 11:1895-901.

41. Borel JC, Pepin JL, Pison C, et al. Long-term adherence with non-invasive ventilation improves prognosis in obese COPD patients. Respirology 2014;19:857-65.

42. Anzueto A, Frutos-Vivar F, Esteban A, et al. Influence of body mass index on outcome of the mechanically ventilated patients. Thorax 2011;66:66-73.

43. Kumar G, Majumdar T, Jacobs ER, et al. Outcomes of morbidly obese patients receiving invasive mechanical ventilation: a nationwide analysis. Chest 2013;144:48-54.

44. Sasabuchi Y, Yasunaga H, Matsui H, et al. The Dose-Response Relationship Between Body Mass Index and Mortality in Subjects Admitted to the ICU With and Without Mechanical Ventilation. Respir Care 2015;60:983-91.

45. Tafelski S, Yi H, Ismaeel F, et al. Obesity in critically ill patients is associated with increased need of mechanical ventilation but not with mortality. J Infect Public Health 2016;9:577-85.

46. Nava S, Bruschi C, Fracchia C, et al. Patient-ventilator interaction and inspiratory effort during pressure support ventilation in patients with different pathologies. Eur Respir J 1997;10:177-83.

47. Vignaux L, Vargas F, Roeseler J, et al. Patient-ventilator asynchrony during non-invasive ventilation for acute respiratory failure: a multicenter study. Intensive Care Med 2009;35:840-6.

48. Carlucci A, Pisani L, Ceriana P, et al. Patient-ventilator asynchronies: may the respiratory mechanics play a role? Crit Care 2013;17:R54.

49. Adler D, Perrig S, Takahashi H, et al. Polysomnography in stable COPD under non-invasive ventilation to reduce patient-ventilator asynchrony and morning breathlessness. Sleep Breath 2012;16:1081-90.

50. Ramsay M, Mandal S, Suh ES, et al. Parasternal electromyography to determine the relationship between patient-ventilator asynchrony and nocturnal gas exchange during home mechanical ventilation set-up. Thorax 2015;70:946-52.

51. Oga T, Taniguchi H, Kita H, et al. Analysis of the relationship between health status and mortality in hypercapnic patients with noninvasive ventilation. Clin Respir J 2017;11:772-80.

52. Tissot A, Jaffre S, Gagnadoux F, et al. Home Non-Invasive
Ventilation Fails to Improve Quality of Life in the Elderly: Results from a Multicenter Cohort Study. PLoS One 2015;10:e0141156.

53. McCarthy B, Casey D, Devane D, et al. Pulmonary rehabilitation for chronic obstructive pulmonary disease. Cochrane Database Syst Rev 2015;(2):CD003793.

54. Esteban C, Arostegui I, Aburto M, et al. Influence of changes in physical activity on frequency of hospitalization in chronic obstructive pulmonary disease. Respirology 2014;19:330-8.

55. Esteban C, Quintana JM, Aburto M, et al. Impact of changes in physical activity on health-related quality of life among patients with COPD. Eur Respir J 2010;36:292-300.

56. Waschki B, Kirsten A, Holz O, et al. Physical activity is the strongest predictor of all-cause mortality in patients with COPD: a prospective cohort study. Chest 2011;140:331-42.

57. Garcia-Rio F, Rojo B, Casitas R, et al. Prognostic value of the objective measurement of daily physical activity in patients with COPD. Chest 2012;142:338-46.

58. Vaes AW, Garcia-Aymerich J, Marott JL, et al. Changes in physical activity and all-cause mortality in COPD. Eur Respir J 2014;44:1199-209.

59. Esteban C, Garcia-Gutierrez S, Legarreta MJ, et al. Oneyear Mortality in COPD After an Exacerbation: The Effect of Physical Activity Changes During the Event. COPD 2016;13:718-25.

60. O'Donnell DE, Revill SM, Webb KA. Dynamic hyperinflation and exercise intolerance in chronic obstructive pulmonary disease. Am J Respir Crit Care Med 2001;164:770-7.

61. Ambrosino N, Guarracino F. Unusual applications of noninvasive ventilation. Eur Respir J 2011;38:440-9.

62. Hill K, Holland AE. Strategies to enhance the benefits of exercise training in the respiratory patient. Clin Chest Med 2014;35:323-36.

63. Márquez-Martín E, Ruiz FO, Ramos PC, et al. Randomized trial of non-invasive ventilation combined with exercise training in patients with chronic hypercapnic failure due to chronic obstructive pulmonary disease. Respir Med 2014;108:1741-51.

64. Salturk C, Karakurt Z, Takir HB, et al. Comparison of exercise capacity in COPD and other etiologies of chronic respiratory failure requiring non-invasive mechanical ventilation at home: retrospective analysis of 1-year followup. Int J Chron Obstruct Pulmon Dis 2015;10:2559-69.

65. Duiverman ML, Wempe JB, Bladder G, et al. Nocturnal non-invasive ventilation in addition to rehabilitation in hypercapnic patients with COPD. Thorax 2008;63:1052-7.

66. Duiverman ML, Wempe JB, Bladder G, et al. Two-year 
home-based nocturnal noninvasive ventilation added to rehabilitation in chronic obstructive pulmonary disease patients: a randomized controlled trial. Respir Res 2011;12:112.

67. Ricci C, Terzoni S, Gaeta M, et al. Physical training and noninvasive ventilation in COPD patients: a meta-analysis. Respir Care 2014;59:709-17.

68. Camillo CA, Osadnik CR, van Remoortel H, et al. Effect of "add-on" interventions on exercise training in individuals with COPD: a systematic review. ERJ Open Res 2016;2. . pii: 00078-2015.

69. Menadue C, Piper AJ, van 't Hul AJ, et al. Non-invasive ventilation during exercise training for people with chronic obstructive pulmonary disease. Cochrane Database Syst Rev 2014;(5):CD007714.

70. Smith LE, Moore E, Ali I, et al. Prognostic variables and scores identifying the end of life in COPD: a systematic review. Int J Chron Obstruct Pulmon Dis 2017;12:2239-56.

71. Nava S, Sturani C, Hartl S, et al. End-of-life decisionmaking in respiratory intermediate care units: a European survey. Eur Respir J 2007;30:156-64.

72. Gore JM, Brophy CJ, Greenstone MA. How well do we care for patients with end stage chronic obstructive pulmonary disease (COPD)? A comparison of palliative care and quality of life in COPD and lung cancer. Thorax 2000;5 5:1000-6.

73. Lanken PN, Terry PB, Delisser HM, et al. An official American Thoracic Society clinical policy statement: palliative care for patients with respiratory diseases and critical illnesses. Am J Respir Crit Care Med 2008;177:912-27.

74. Higginson IJ, Bausewein C, Reilly CC, et al. An integrated palliative and respiratory care service for patients with advanced disease and refractory breathlessness: a randomised controlled trial. Lancet Respir Med 2014;2:979-87.

75. Cuomo A, Delmastro M, Ceriana P, et al. Noninvasive mechanical ventilation as a palliative treatment of acute respiratory failure in patients with end-stage solid cancer. Palliat Med 2004;18:602-10.

76. Curtis JR, Cook DJ, Sinuff T, et al. Noninvasive positive pressure ventilation in critical and palliative care settings: understanding the goals of therapy. Crit Care Med 2007;35:932-9.

77. Roca O, Riera J, Torres F, et al. High-flow oxygen therapy in acute respiratory failure. Respir Care 2010;5 5:408-13.

78. Tiruvoipati R, Lewis D, Haji K, et al. High-flow nasal oxygen vs high-flow face mask: a randomized crossover trial in extubated patients. J Crit Care 2010;25:463-8.

79. Cuquemelle E, Pham T, Papon JF, et al. Heated and humidified high-flow oxygen therapy reduces discomfort during hypoxemic respiratory failure. Respir Care 2012;57:1571-7.

80. Maggiore SM, Idone FA, Vaschetto R, et al. Nasal highflow versus Venturi mask oxygen therapy after extubation. Effects on oxygenation, comfort, and clinical outcome. Am J Respir Crit Care Med 2014;190:282-8.

81. Ritchie JE, Williams AB, Gerard C, et al. Evaluation of a humidified nasal high-flow oxygen system, using oxygraphy, capnography and measurement of upper airway pressures. Anaesth Intensive Care 2011;39:1103-10.

82. Wettstein RB, Shelledy DC, Peters JI. Delivered oxygen concentrations using low-flow and high-flow nasal cannulas. Respir Care 2005;50:604-9.

83. Nishimura M. High-flow nasal cannula oxygen therapy in adults. J Intensive Care 2015;3:15.

84. Hernández G, Vaquero C, Gonzalez P, et al. Effect of Postextubation High-Flow Nasal Cannula vs Conventional Oxygen Therapy on Reintubation in Low-Risk Patients: A Randomized Clinical Trial. JAMA 2016;315:1354-61.

85. Hernández G, Vaquero C, Colinas L, et al. Effect of Postextubation High-Flow Nasal Cannula vs Noninvasive Ventilation on Reintubation and Postextubation Respiratory Failure in High-Risk Patients: A Randomized Clinical Trial. JAMA 2016;316:1565-74.

86. Stéphan F, Barrucand B, Petit P, et al. High-Flow Nasal Oxygen vs Noninvasive Positive Airway Pressure in Hypoxemic Patients After Cardiothoracic Surgery: A Randomized Clinical Trial. JAMA 2015;313:2331-9.

87. Frat JP, Thille AW, Mercat A, et al. High-flow oxygen through nasal cannula in acute hypoxemic respiratory failure. N Engl J Med 2015;372:2185-96.

88. Millar J, Lutton S, O'Connor P. The use of high-flow nasal oxygen therapy in the management of hypercarbic respiratory failure. Ther Adv Respir Dis 2014;8:63-4.

89. Pilcher J, Eastlake L, Richards M, et al. Physiological effects of titrated oxygen via nasal high-flow cannulae in COPD exacerbations: A randomized controlled cross-over trial. Respirology 2017;22:1149-55.

90. Bräunlich J, Kohler M, Wirtz H. Nasal highflow improves ventilation in patients with COPD. Int J Chron Obstruct Pulmon Dis 2016;11:1077-85.

Cite this article as: Shah NM, D'Cruz RF, Murphy PB. Update: non-invasive ventilation in chronic obstructive pulmonary disease. J Thorac Dis 2018;10(Suppl 1):S71-S79. doi: $10.21037 /$ jtd.2017.10.44 